\title{
Avaliação das Características de Transporte em Membranas de Poliamida 66 Preparadas com Diferentes Solventes
}

\author{
Patrícia Poletto, Jocelei Duarte, Matias S. Lunkes, Venina dos Santos, Mára Zeni \\ Centro de Ciências Exatas e Tecnologia, UCS \\ Carla S. Meireles, Guimes R. Filho \\ Instituto de Química, UFU \\ Aldo Bottino \\ Dipartimento di Chimica e Chimica Industriale, Università di Genova-Italy
}

\begin{abstract}
Resumo: Membranas de poliamidas alifáticas são muito utilizadas como barreiras seletivas em processos de microfiltração e ultrafiltração. Neste trabalho membranas de poliamida 66 (PA 66) foram preparadas pelo método de inversão de fases e caracterizadas para aplicação em processos de ultrafiltração. As membranas de PA 66 foram preparadas utilizando dois solventes diferentes, ácido fórmico (AF) e ácido clorídrico $(\mathrm{HCl})$ e água como não-solvente. A análise por Espectroscopia de Infravermelho com Transformada de Fourier (FT-IR) mostrou que a estrutura química da PA 66 não foi alterada com o uso dos solventes na preparação das membranas. O ensaio de compactação com água pura realizado a $1500 \mathrm{kPa}$ de pressão revelou que as membranas preparadas em AF sofreram maior compactação na sua estrutura apresentando fluxo de permeado em torno de $17 \mathrm{~L} \cdot \mathrm{m}^{-2} \cdot \mathrm{h}^{-1}$ enquanto a membrana preparada em $\mathrm{HCl}$ apresentou fluxo de $22,2 \mathrm{~L} \cdot \mathrm{m}^{-2} \cdot \mathrm{h}^{-1}$. Nos ensaios de ultrafiltração (UF), ambas as membranas apresentaram valores de retenção próximos a $70 \%$ para albumina de ovo (45 kDa) e $80 \%$ para albumina sérica bovina $(69 \mathrm{kDa})$. Com esse resultado, pode-se concluir que ambas as membranas apresentaram ponto de corte nominal para aplicações em processos de UF.
\end{abstract}

Palavras-chave: Poliamida 66, membranas poliméricas, inversão de fases, ultrafiltração.

\section{Evaluation of Transport Characteristics in Polyamide 66 Membranes Prepared with Different Solvents}

\begin{abstract}
In the present study, polyamide 66 (PA 66) membranes were prepared by phase inversion method and characterized in order to verify their potential application in ultrafiltration processes. PA 66 membranes were prepared using two different solvents, formic acid (FA) and hydrochloric acid $(\mathrm{HCl})$, and water as a non-solvent. Fourier-transform infrared spectroscopy (FT-IR) showed that the chemical structure of PA 66 was not altered by the use of solvents in the preparation of membranes. The compaction experiment with pure water performed at a pressure of $1500 \mathrm{kPa}$ revealed that membranes prepared with FA undergo greater compaction of its structure and had a permeate flux value of approximately $17 \mathrm{~L} \cdot \mathrm{m}^{-2} \cdot \mathrm{h}^{-1}$ whereas the membrane prepared with $\mathrm{HCl}$ had a permeate flux of $22.2 \mathrm{~L} \cdot \mathrm{m}^{-2} \cdot \mathrm{h}^{-1}$. In the ultrafiltration experiment, both membranes had retention values around $70 \%$ for egg albumin and $80 \%$ for bovine serum albumin. Based on this result, one concludes that both membranes had nominal cut off values for application in ultrafiltration processes.
\end{abstract}

Keywords: Polyamide 66, polymeric membranes, phase inversion, ultrafiltration.

\section{Introdução}

Atualmente, a tecnologia de membranas é aplicada em muitos processos industriais apresentando inúmeras vantagens, como a realização de forma contínua com baixo consumo energético e a facilidade em ser combinado com outros processos de separação.

O estudo de diferentes materiais aplicados ao desenvolvimento de membranas e o uso de novas técnicas na sua preparação tem sido o foco de muitos trabalhos desenvolvidos no mundo. Apesar dos processos de separação por membranas serem empregados em escala industrial, uma das limitações a ser superada é o custo elevado do sistema filtrante.

Entre os inúmeros materiais utilizados na preparação de membranas está a poliamida. A poliamida 66 (PA 66) quando utilizada na forma de filmes, por exemplo, apresenta alta resistência a temperatura e boas propriedades de barreira, sendo que a taxa de permeação dos filmes, depende da espessura, grau de cristalinidade, temperatura e pressão aplicada ${ }^{[1]}$.

A preparação de membranas de poliamida obtidas pelo método de inversão de fases (IF) é relatada por muitos autores ${ }^{[2-8]}$.
Yao et al. ${ }^{[4]}$ prepararam membranas de poliamida 6 usando ácido clorídrico como solvente e observaram que com a variação do não-solvente utilizado, diferentes estruturas morfológicas eram obtidas resultando em variações no fluxo de água. Quando soluções mais básicas que a água foram usadas, poros de forma alongada e estruturas tipo esponja foram obtidas resultando em redução do fluxo de água em torno de $50 \%$, porém com elevada rejeição a proteína albumina bovina.

A miscibilidade, cristalinidade e morfologia de membranas a partir de blendas de diferentes poliamidas (PA 6, PA 66, PA 69) e poli(álcool vinílico) (PVA) foram estudadas por Rawajfeh et al. [5-6]. A adição de PVA apresentou efeito positivo na hidrofilia e na morfologia da membrana, para aplicação em escala de nanofiltração e osmose inversa.

Lin et al. ${ }^{[9]}$ prepararam membranas de poliamida 66 variando a composição da solução polimérica (não-solvente/solvente/ poliamida 66) e do banho de coagulação (não solvente/solvente). As membranas foram caracterizadas por microscopia eletrônica

Autor para correspondência: Mara Zeni, Centro de Ciências Exatas e Tecnologia, Universidade de Caxias do Sul - UCS, CP 1352, CEP 95070-560,

Caxias do Sul, RS, Brasil, e-mail: mzandrad@ucs.br 
com alta resolução para avaliar as diferentes formações da morfologia cristalina de escala nanométrica como por exemplo, esferulitos, nano-grãos, nano-poros e lamelas.

Modificações na estrutura química de poliamida aromática aplicada na preparação de filmes densos favoreceram as propriedades mecânicas, térmicas e de transporte para uso em sistemas de separação de gases $^{[10]}$.

Em trabalhos anteriores ${ }^{[11,12]}$ realizados por nosso grupo de pesquisa, membranas de poliamida 66 foram preparadas utilizando ácido clorídrico como solvente. Zeni et al. ${ }^{[11]}$ avaliaram o comportamento da membrana preparada em diferentes concentrações de polímero, e mostraram que a membrana preparada em concentração mais elevada apresentava fluxo superior. A adição de poli(vinil pirrolidona) também foi estudada e os resultados demonstraram diferenças significativas na estrutura assimétrica da membrana com redução da espessura de camada densa e aumento considerável no fluxo de permeado ${ }^{[12]}$.

Visando o desenvolvimento de tecnologias de separação por membranas, foram preparadas neste trabalho, membranas de poliamida 66 suportadas em tecido de poliéster pelo método de inversão de fases utilizando dois diferentes solventes, ácido fórmico e ácido clorídrico. O trabalho apresenta a caracterização de membranas de PA 66 preparadas em $\mathrm{HCl}$, o que é pouco discutido na literatura, e compara com membranas preparadas em ácido fórmico.

Para avaliar o efeito dos diferentes solventes, as membranas foram caracterizadas quanto a sua estrutura morfológica e propriedades de transporte como fluxo de permeado e retenção de proteínas.

\section{Experimental}

\section{Materiais}

Poliamida 66 (PA 66) foi fornecida pela Alfa Polímeros, com massa molar média de $161.000 \mathrm{~g} \cdot \mathrm{mol}^{-1}$. Ácido fórmico (HCOOH - Merck 98\%) e ácido clorídrico ( $\mathrm{HCl}$ - Merck 37\%) foram utilizados como solventes e água deionizada $(2,44 \mu \mathrm{S})$ como não-solvente para PA 66. Tecido de poliéster, com espessura de $180 \mu$, foi usado como suporte mecânico para as membranas. Proteínas de albumina de ovo e albumina serum bovina com massa molar de 45 e $69 \mathrm{kDa}$, respectivamente foram utilizadas nos ensaios de seletividade das membranas.

\section{Preparação das membranas suportadas pelo método de inversão de fases}

Para obtenção da membrana, o suporte de poliéster foi mergulhado na solução de PA 66 para o recobrimento total da sua superfície para posterior formação do filme polimérico. $\mathrm{O}$ suporte impregnado foi mantido na posição vertical até que o excesso de solução fosse removido. Os solventes foram evaporados à temperatura de $35^{\circ} \mathrm{C}$ por 8 horas. A formação da membrana é finalizada com o banho de não solvente (água) à temperatura de $20{ }^{\circ} \mathrm{C}$ pelo método de inversão de fases mantendo a membrana submersa por quatro horas. A espessura final das membranas suportadas variou de 245 à $255 \mu \mathrm{m}$.

\section{Análise por espectroscopia de infravermelho (FT-IR)}

As membranas foram analisadas por FT-IR para avaliar o efeito dos diferentes ácidos na estrutura da PA 66. A análise foi realizada por meio de 32 varreduras, no intervalo de 4000 à $400 \mathrm{~cm}^{-1}$, com resolução de $4 \mathrm{~cm}^{-1}$, em um equipamento FT-IR Nicolet iS10 - Thermo Scientific.

\section{Microscopia eletrônica de varredura (MEV)}

A análise de Microscopia Eletrônica de Varredura (MEV) da superfície e da secção transversal das membranas suportadas foi realizada pelo Departamento de Química e Química Industrial da Universidade de Genova, Itália, utilizando o microscópio Leica Stereocan 440. As amostras foram cuidadosamente fraturadas em nitrogênio líquido e metalizadas a partir de um sputtering com uma fina camada de ouro antes de sua caracterização.

\section{Fluxo de água pura}

O fluxo de água pura das membranas foi medido utilizando sistema de filtração frontal com área de membrana em torno de $16,5 \mathrm{~cm}^{2}$. As membranas foram compactadas usando água como alimentação a uma pressão constante de $1500 \mathrm{kPa}$ durante 90 minutos. O fluxo de água foi calculado através do volume permeado usando a Equação 1.

$$
J_{w}=\frac{V}{A \Delta t}
$$

sendo, $J_{w}$ é o fluxo de água $\left(\mathrm{L} \cdot \mathrm{m}^{-2} \cdot \mathrm{h}^{-1}\right), V$ é o volume permeado (L), $A$ é a área da membrana $\left(\mathrm{m}^{2}\right)$ e $\Delta t$ é o tempo de permeação (h).

\section{Retenção de proteínas}

A retenção apresentada pelas membranas foi medida usando soluções de proteína de diferentes massas molares como a albumina de ovo (45 kDa) e albumina serum bovina (BSA) $(69 \mathrm{kDa})$. As soluções protéicas foram preparadas individualmente na concentração de 100 ppm. O fluxo de permeado das soluções protéicas foi medido a pressão constante de 15 bar. As concentrações das soluções protéicas na alimentação $\left(C_{f}\right)$ e no permeado $\left(C_{p}\right)$ foram determinadas por meio das leituras da absorbância no comprimento de onda de $280 \mathrm{~nm}$ usando espectrofotômetro de ultravioleta - Genesys 10 UV, Termo Spectronic (UV-Visível). A retenção da proteína (\%RP) foi calculada pela Equação 2:

$$
\% R P=\left(1-\frac{C p}{C f}\right) \times 100
$$

\section{Resultados e Discussão}

\section{Análise por infravermelho das membranas de PA 66}

A maioria dos trabalhos ${ }^{[8,9,13]}$ que descreve a preparação de membranas de poliamida por inversão de fases utilizam ácido fórmico como solvente. $\mathrm{O}$ ácido clorídrico é um ácido inorgânico forte, extremamente reativo na concentração de $37 \%$. Porém, a poliamida utilizada na preparação das membranas usando o $\mathrm{HCl}$ e ácido fórmico (AF) como solvente, não sofreu alterações em sua estrutura, analisada por FT-IR (Figura 1). A região em torno de $3300 \mathrm{~cm}^{-1}$ corresponde às frequências de vibração molecular do estiramento da ligação N-H e a região em torno de 2930 a $2860 \mathrm{~cm}^{-1}$ às do grupo $\mathrm{CH}_{2}$. A região de $1365 \mathrm{~cm}^{-1}$ corresponde ao estiramento da ligação $\mathrm{C}=\mathrm{O}$ característico do grupo amida e em $1416 \mathrm{~cm}^{-1} \mathrm{o}$ estiramento do grupo C-N.

\section{Morfologia das membranas suportadas}

As Figuras 2 e 3 ilustram as micrografias da superfície das membranas. Foi observado um bom recobrimento da superfície do suporte de poliéster tanto para as membranas preparadas com $\mathrm{HCl}$ quanto para as membranas preparadas com AF. No detalhe da Figura 1a está a imagem do suporte de poliéster. 
As membranas apresentaram diferentes morfologias na seção transversal, com variação na estrutura dependendo do solvente utilizado. Em ambas as membranas a impregnação ocorreu em toda a extensão do suporte, mostrando uma boa deposição de poliamida tanto na superfície quanto na seção transversal. Como observado nas

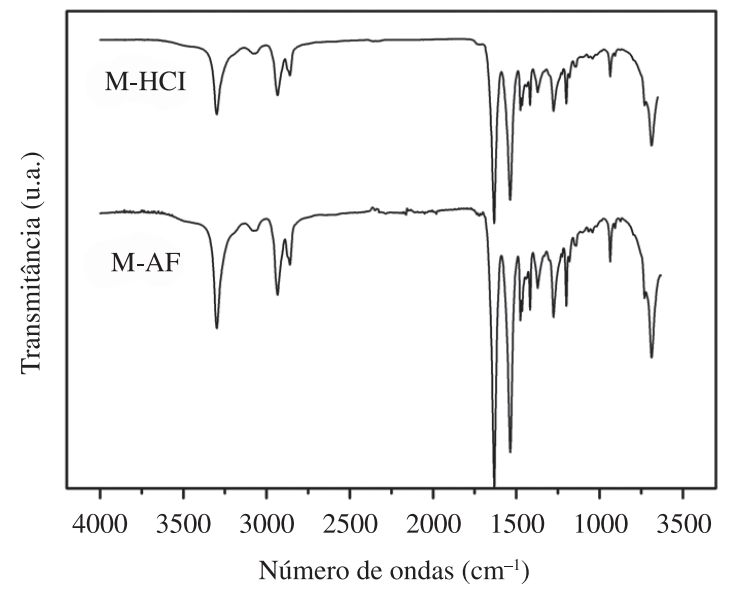

Figura 1. Espectro de FT-IR das membranas de poliamida 66 preparadas em $\mathrm{HCl}(\mathrm{M}-\mathrm{HCl})$ e em AF (M-AF).

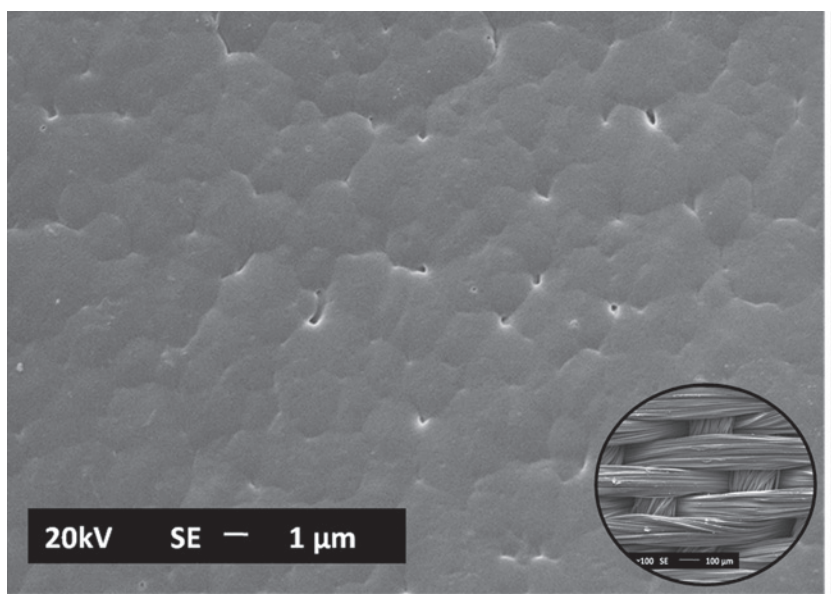

(a) imagens das Figuras 4 e 5, as membranas apresentaram formação de aglomerados, não ocorrendo a formação de poros bem definidos ao longo da seção transversal das membranas. A membrana preparada em AF apresentou formação mais esponjosa enquanto a membrana preparada em $\mathrm{HCl}$ apresentou canais maiores na sua morfologia. Com esse resultado fica evidente que o solvente utilizado causa alterações na morfologia da membrana, o que contribui para diferentes comportamentos de permeação.

Geralmente, as membranas de poliamida preparadas pelo método de inversão de fases, utilizando $\mathrm{HCl}$ ou $\mathrm{AF}$, apresentam estruturas porosas ao longo da seção transversal ${ }^{[8-13]}$. A formação mais densa observada nas membranas preparadas neste trabalho pode estar relacionada à longa etapa de evaporação para a formação da camada de poliamida sobre o suporte de poliéster. A diferença na estrutura morfológica tem grande influência no desempenho das membranas relacionado ao fluxo de permeado e retenção, como será observado nos resultados discutidos a seguir.

\section{Fluxo de água pura durante a compactação da membrana}

As membranas de PA 66 preparadas foram submetidas à compactação com água pura antes do teste de rejeição. $\mathrm{O}$ efeito do tempo de compactação no fluxo de permeado para as membranas suportadas é mostrado na Figura 6. Este ensaio foi realizado com

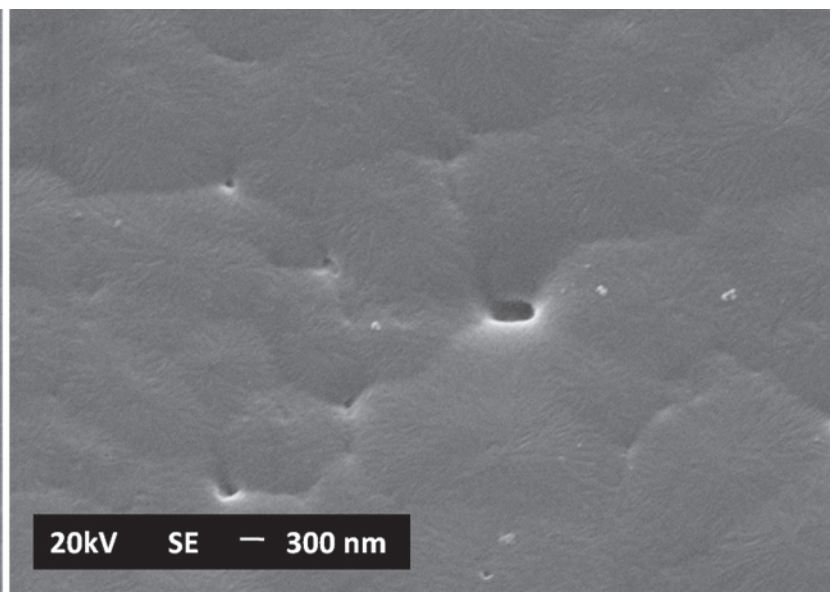

(b)

Figura 2. Micrografia (MEV) da superfície das membranas suportadas de PA 66 preparadas em AF a) escala $1 \mu \mathrm{m}$ e b) escala $300 \mathrm{~nm}$.

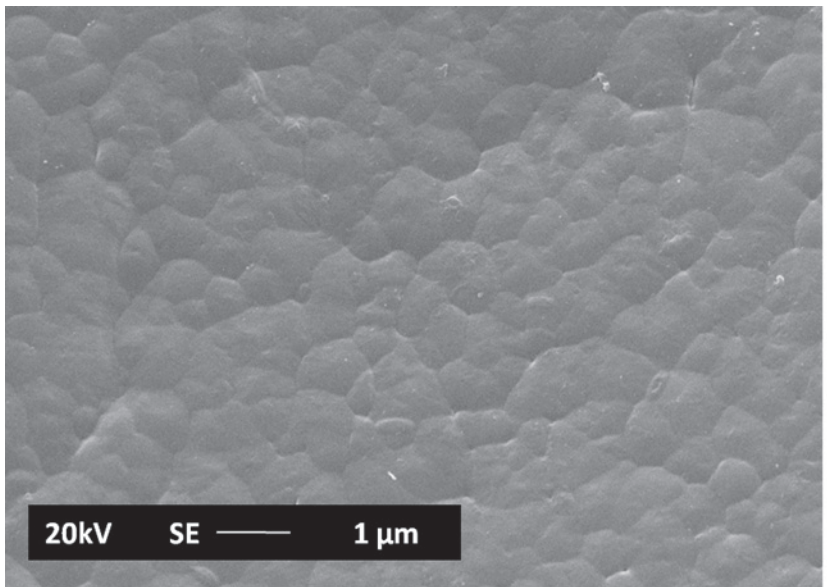

(a)

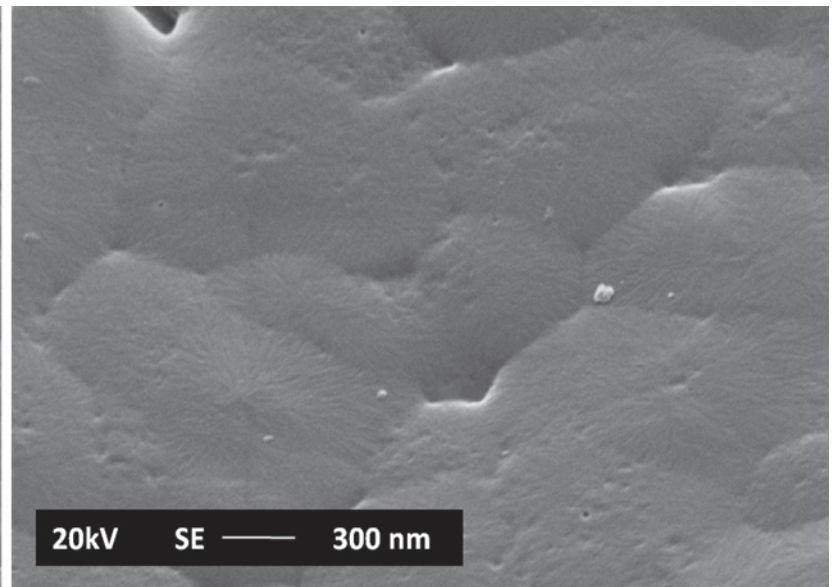

(b)

Figura 3. Micrografia (MEV) da superfície das membranas suportadas de PA 66 preparadas em $\mathrm{HCl}$ a) escala $1 \mu \mathrm{m}$ e b) escala $300 \mathrm{~nm}$. 


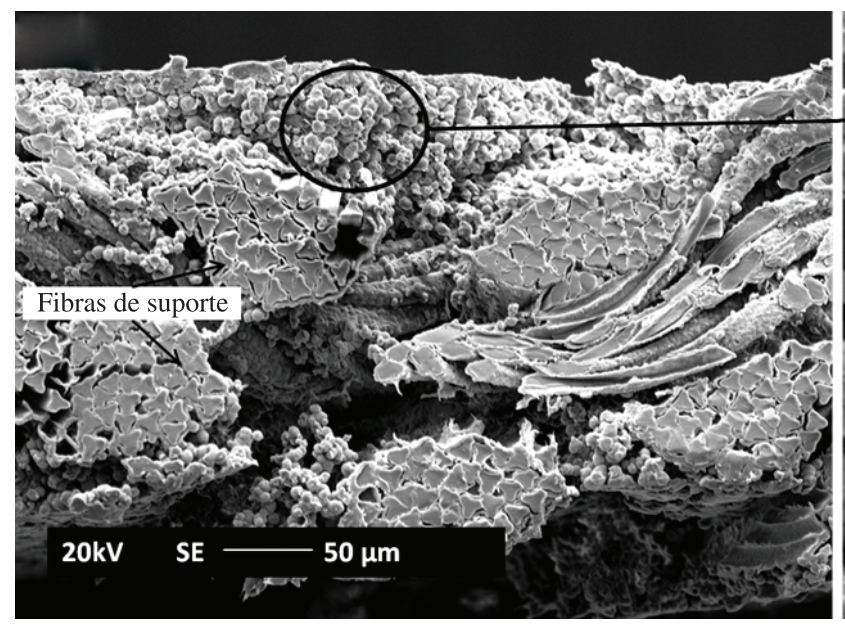

(a)

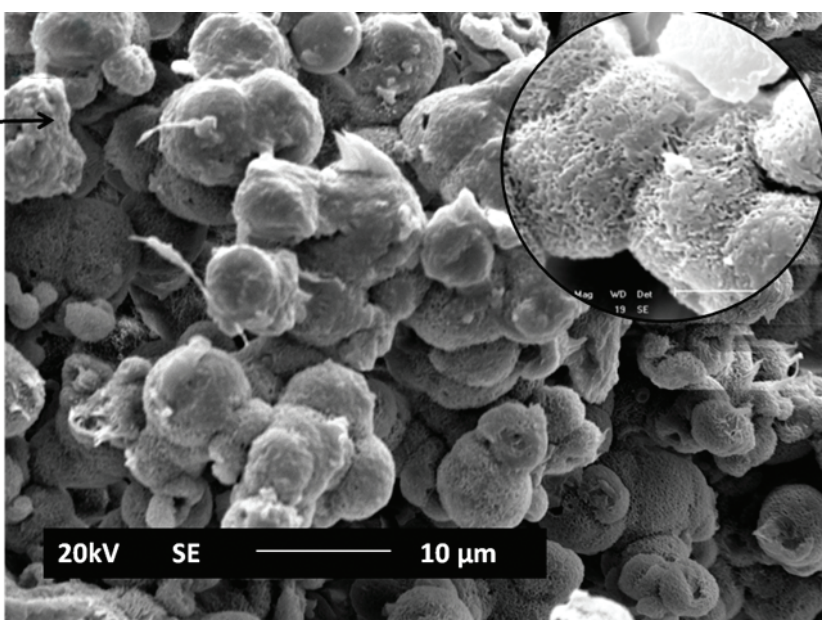

(b)

Figura 4. Micrografia (MEV) da seção transversal da membrana suportada preparada com AF a) seção transversal b) detalhe da camada de poliamida.

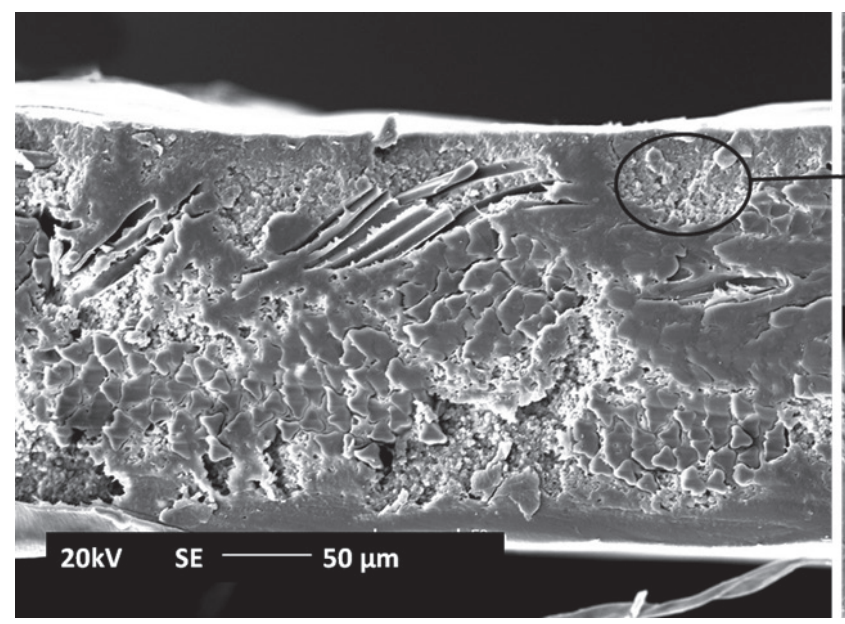

(a)

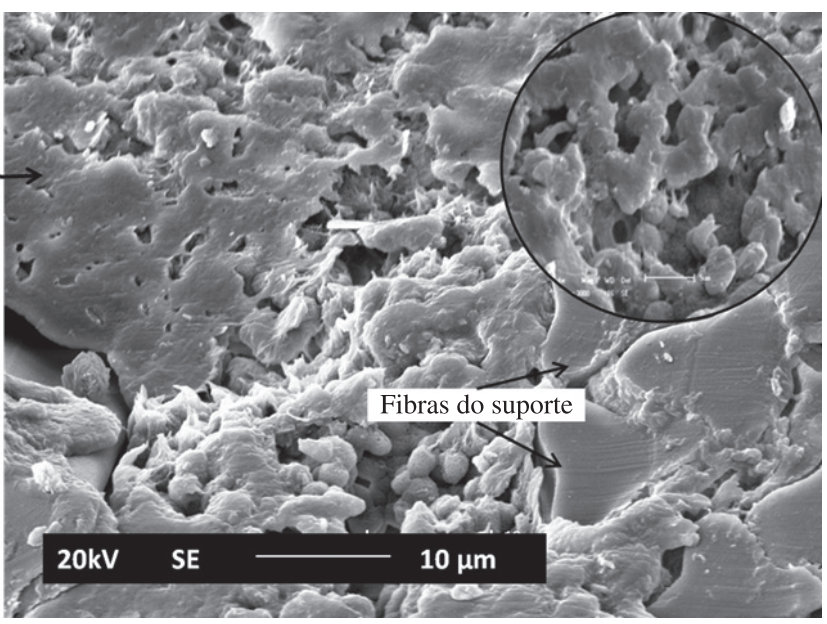

(b)

Figura 5. Micrografia (MEV) da seção transversal da membrana suportada preparada com $\mathrm{HCl}$ a) seção transversal b) detalhe da camada de poliamida 66.

água pura na pressão de $1500 \mathrm{kPa}$ até que o fluxo constante fosse atingido.

Durante a compactação, a estrutura da membrana torna-se mais densa, reduzindo a porosidade e conseqüentemente, diminuindo o fluxo de permeado, o qual depende da pressão aplicada e das características estruturais da membrana ${ }^{[14-16]}$. Foi observado que o fluxo diminui, gradualmente, devido à compactação em função do tempo. Após 50 minutos de compactação, considerou-se que o fluxo em estado estacionário foi atingido.

Ao final dos 90 minutos de permeação, o fluxo para membrana M-AF foi de 17,2 L.m ${ }^{-2} \cdot h^{-1}$ enquanto para membrana $\mathrm{M}-\mathrm{HCl}$ foi de 22,2 $\mathrm{L} \cdot \mathrm{m}^{-2} \cdot \mathrm{h}^{-1}$. Porém, o fluxo inicial da membrana $\mathrm{M}-\mathrm{HCl}$ é superior ao da membrana M-AF, o que indica que essa membrana sofreu maior compactação em sua estrutura. A diferença entre os valores de fluxo das membranas pode estar relacionada com as diferentes estruturas formadas na seção transversal das membranas discutidas anteriormente, o que influencia diretamente seu comportamento nos ensaios de permeação.

Retenção de proteínas e ponto de corte molar (MWCO - Molecular Weight Cut-Off)

Os ensaios de retenção, foram realizados com àgua pura após o fluxo estabilizado. A Figura 7 mostra o comportamento das membranas de PA 66 quando diferentes soluções protéicas foram utilizadas na alimentação. A elevada dispersão dos resultados de fluxo e retenção (desvio padrão) é atribuída à difícil reprodutibilidade do processo de preparação das membranas, o qual é realizado manualmente.

A membrana preparada com $\mathrm{HCl}$ como solvente apresentou valores de fluxo maiores quando comparada a membrana preparada em $\mathrm{AF}$, tanto para a água pura, como mostrado anteriormente durante a compactação, quanto para as soluções protéicas. Ambas as membranas demonstraram a mesma tendência para os valores de fluxo de permeado (água $>$ albumina de ovo $>$ BSA). A redução no fluxo deve-se ao aumento da massa molar dos solutos, isto é, o soluto de menor massa molar passa mais facilmente pela membrana.

O principal objetivo do ensaio com solutos de diferentes massas molares foi investigar a retenção para caracterizar o ponto de corte molar da membrana (MWCO). Segundo Arthanareeswaran et al. ${ }^{[17]}$, o ponto de corte molar de uma membrana pode ser estabelecido como a massa molar igual a do soluto no qual a retenção apresentada pela membrana for maior que $80 \%$. Neste trabalho, ambas as membranas apresentaram valores de retenção em torno de $70 \%$ para albumina de ovo $(45 \mathrm{kDa})$ e maior que $80 \%$ para BSA $(69 \mathrm{kDa})$. Com a retenção da proteína BSA acima de $80 \%$, ambas as membranas poderiam ser utilizadas em processos de ultrafiltração para retenção de solutos com massa molar maior que $69 \mathrm{kDa}$. 


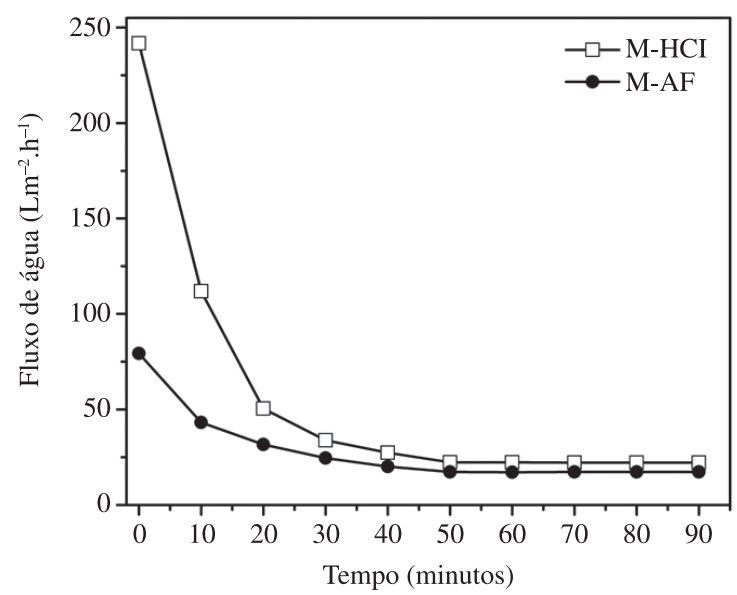

Figura 6. Compactação das membranas de PA 66 suportadas preparadas em $\mathrm{AF}(\mathrm{M}-\mathrm{AF})$ e $\mathrm{HCl}(\mathrm{M}-\mathrm{HCl})$.

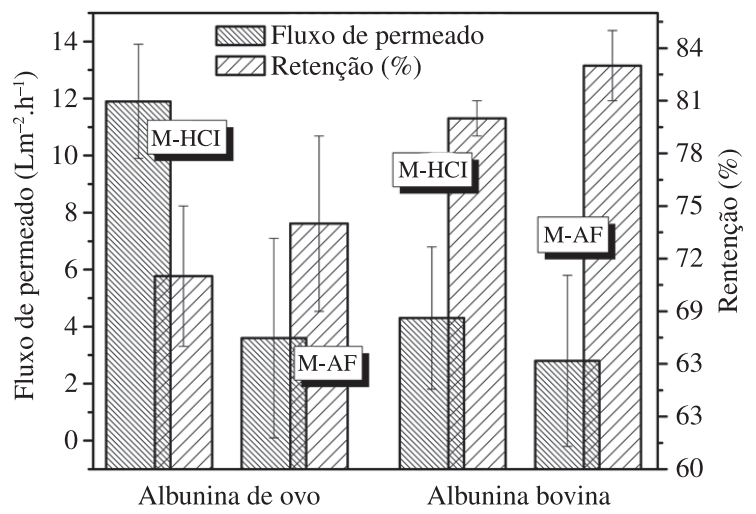

Figura 7. Ensaio de ultrafiltração das membranas de PA 66 com diferentes proteínas.

\section{Conclusões}

O ácido clorídrico, apesar de pouco usado na preparação de membranas de poliamida, quando comparado ao ácido fórmico, o qual é geralmente empregado, apresentou resultados satisfatórios de fluxo e retenção, mostrando potencial para uso na preparação de membranas. Na análise por FT-IR não foram observadas alterações na estrutura química na membrana quando utilizado $\mathrm{HCl}$ e ácido fórmico como solventes. A morfologia das membranas observada por MEV apresentaram diferenças na formação de poros, o que resultou em diferentes valores de fluxo e rejeição.

Os resultados apresentados pelas membranas no teste de rejeição de proteínas foram de $70 \%$ para a albumina de ovo e $83 \%$ para a BSA, indicando que a aplicação mais adequada dessas membranas é em processos de separação com solutos de massa molar maior que $69 \mathrm{kDa}$.
Avaliando os valores de fluxo e rejeição apresentados, a membrana preparada em $\mathrm{HCl}$ apresentou comportamento mais favorável para aplicação em processos de separação, visto que sua retenção é muito próxima e seu fluxo é superior ao da membrana preparada em AF.

\section{Agradecimentos}

Os autores agradecem ao CNPq e a Hidro Filtros do Brasil pelo apoio financeiro.

\section{Referências Bibliográficas}

1. Kohan, M. I. - "Nylon plastics handbook", Hanser, New York (1995).

2. Scott, K. - "Handbook of industrial membranes", Elsevier Advanced Tecnology, Oxford (1995).

3. Carvalho, R. B.; Borges, C. P. \& Nóbrega, R. - Polímeros, 11, p.65 (2001).

4. Yao, C. W.; Burford, R. P.; Fane, A. G. \& Fell, C. J. D. - J. Membr. Sc., 38, p.113 (1988). http://dx.doi.org/10.1016/S0376-7388(00)80874-1

5. Rawajfeh, A. E. - Desalination, 179, p.265 (2005).

6. Rawajfeh, A. E.; Al-Salah, H. A.; Al-Shamaileh, E. \& Donchev, D. - Desalination, 227, p.120 (2008).

7. Torres, M. R.; Soriano, E.; Abajo, J. \& De La Campa, J. G. - J. Membr. Sci., 81, p.31 (1993). http://dx.doi.org/10.1016/0376-7388(93)85029-V

8. Leite, A. M. D.; Araújo, E. M.; Lira, H. L.; Barbosa, R. \& Ito, E. N. - Polímeros, 19, p.271 (2009). http://dx.doi.org/10.1590/S010414282009000400005

9. Lin, D. J.; Chang, C. L.; Lee, C. K. \& Cheng, L. P. - Eur. Polym. J., 42, p.356 (2006). http://dx.doi.org/10.1016/j.eurpolymj.2005.07.007

10. Espeso, J.; Lozano, A. E.; De La Campa, J. G. \& Abajo, J. - J. Membr. Sci., 280, p.659 (2006). http://dx.doi.org/10.1016/j. memsci.2006.02.023

11. Zeni, M.; Riveros, R.; Souza, J. F.; Mello, K.; Meireles, C. \& Rodrigues, G. F.- Desalination, 221 (2008) 294-297. http://dx.doi.org/10.1016/j. desal.2007.03.012

12. Poletto, P.; Duarte, J.; Thürmer, M. B. \& Zeni, M. - Desalinat. Water Treat., 27, p.76 (2011). http://dx.doi.org/10.5004/dwt.2011.2055

13. Shih, C. H.; Gryte, C. C. \& Cheng, L. P. - J. Appl. Polym. Sci., 96, p.944 (2005). http://dx.doi.org/10.1002/app.21545

14. Persson, K. M.; Gekas, V. \& Tragargh, G. - J. Membr. Sci., 100, p.155 (1995). http://dx.doi.org/10.1016/0376-7388(94)00263-X

15. Mulder, M. - "Basic principles of membrane technology", 2nd ed., Kluwer Academic Publishers, Dordrecht (1996). http://dx.doi. org/10.1007/978-94-009-1766-8

16. Arthanareeswaran, G.; Devi, T. K. S. \& Raajenthiren, M. - Sep. Purif. Technol., 64, p.38 (2008). http://dx.doi.org/10.1016/j. seppur.2008.08.010

17. Arthanareeswaran G.; Latha, C. S.; Mohan, D.; Raajenthiren, M. \& Srinivasan, K. - Sep. Purif. Technol., 41, p.2895 (2006).

Enviado: 08/02/11 Reenviado: 01/09/11 Aceito: 04/09/11 